\title{
The Production of Formic Acid from Polysaccharides and Biomass via One-pot Hydrolysis-Oxidation in the Presence of Mo-V-P Heteropoly Acid Catalyst
}

\author{
Nikolay V. Gromov*a,b, Tatiana B. Medvedeva ${ }^{a}$, \\ Yulia A. Rodikova ${ }^{a}$, Andrey V. Pestunov ${ }^{c}$, \\ Elena G. Zhizhina ${ }^{a}$ and Oxana P. Taran ${ }^{a, b}$ \\ ${ }^{a}$ Boreskov Institute of Catalysis $S B R A S$ \\ 5 Lavrentiev, Novosibirsk, 630090, Russia \\ ${ }^{b}$ Novosibirsk State Technical University \\ 20 Karl Marx, Novosibirsk, 630073, Russia \\ 'Institute of Chemistry and Chemical Technology SB RAS \\ FRC "Krasnoyarsk Science Center SB RAS” \\ 50/24 Akademgorodok, Krasnoyarsk, 660036, Russia
}

The aim of the work is to investigate the one-pot hydrolysis-oxidation of different lignocellulose feedstocks: hemicelluloses xylan and arabinogalactan as well as lignocellulose biomass (sulfate pulp, waste paper, silver grass and aspen wood). The target product of the process is formic acid. It is a valuable product which seems to be very perspective reducing agent or hydrogen source. The experiments have been carried out in the solutions of bifunctional Mo-V-P heteropoly acid catalyst which has the composition $\mathrm{Co}_{0.6} \mathrm{H}_{3.8} \mathrm{PMo}_{10} \mathrm{~V}_{2} \mathrm{O}_{40}$. The yield of formic acid equal to 40-43 mol \% has been reached from hemicelluloses at 90-120 ${ }^{\circ} \mathrm{C}$. At temperature $150{ }^{\circ} \mathrm{C}$ the formic acid yields 53,45 , 29 and $24 \mathrm{~m} / \mathrm{m} \%$ have been achieved from aspen wood, silver grass, sulfate cellulose and waste paper, respectively.

Keywords: hydrolysis-oxidation, lignocellulose biomass, arabinogalactan, xylan, formic acid, bifunctional catalyst, heteropoly acid, molybdenum, vanadium.

Citation: Gromov N.V., Medvedeva T.B., Pestunov A.V., Taran O.P. The production of formic acid from polysaccharides and biomass via one-pot hydrolysis-oxidation in the presence of Mo-V-P heteropoly acid catalyst, J. Sib. Fed. Univ. Chem., 2018, 11(1), 56-71. DOI: 10.17516/1998-2836-0058.

(c) Siberian Federal University. All rights reserved

* Corresponding author E-mail address: gromov@catalysis.ru 


\title{
Получение муравьиной кислоты из полисахаридов \\ и биомассы одностадийным гидролизом-окислением \\ в присутствии растворимых катализаторов \\ Мо-V-P гетерополикислот
}

\author{
Н.В. Громов ${ }^{\text {a,б, }}$, Т.Б. Медведева ${ }^{a}$, Ю.А. Родикова ${ }^{a}$, \\ А.В. Пестунов ${ }^{\mathrm{B}}$, Е.Г. Жижина ${ }^{\mathrm{a}}$, О.П. Таран ${ }^{\mathrm{a}, \bar{\sigma}}$ \\ ${ }^{a}$ Институт катализа им. Г.К. Борескова СО РАН \\ Россия, 630090, Новосибирск, пр. Академика Лаврентьева, 5 \\ ${ }^{6}$ Новосибирский государственный технический университет \\ Россия, 630073, Новосибирск, пр. Карла Маркса, 20 \\ ${ }^{6}$ Институт химии и химической технологии СО РАН \\ ФИЦ «Красноярский научный центр СО РАН» \\ Россия, 660036, Красноярск, Академгородок, 50/24
}

\begin{abstract}
Проведено исследование одностадийного гидролиза-окисления различного лигноцеллюлозного сырья (гемицеллюлоз: ксилан и арабиногалактан, а также образиов лигноцеллюлозы: сульфатная целлюлоза, газетная бумага, мискантус, древесина осины) в муравьиную кислотуценный продукт, перспективный восстановитель и/или источник водорода. Исследования выполнены в растворе бифункционального катализатора Мо-V-P гетерополикислоты (ГПК) $\mathrm{Co}_{0.6} \mathrm{H}_{3.8} \mathrm{PMo}_{10} \mathrm{~V}_{2} \mathrm{O}_{40}$. Муравьиная кислота получена из гемицеллюлоз с выходом до 40-43 мол. \% при 90-120 ${ }^{\circ} \mathrm{C}$. При $150^{\circ} \mathrm{C}$ достигнуты выходы муравьиной кислоты 53, 45, 29 и 24 мас. \% для древесины осины, мискантуса, сульфатной целлюлозы и газетной бумаги соответственно.
\end{abstract}

Ключевые слова: гидролиз-окисление, лигноцеллюлозная биомасса, арабиногалактан, ксилан, муравьиная кислота, бифункциональный катализатор, гетерополикислота, молибден, ванадий.

\section{Введение}

Постоянное уменьшение запасов высококачественных и относительно доступных ископаемых источников углеводородов, а также постоянный рост мирового энергопотребления и потребностей общества в сырье для развития экономики и повышения уровня жизни вызывают необходимость поиска альтернативной сырьевой базы для устойчивого развития промышленности и энергетики. В число перспективных видов альтернативного сырья включают лигноцеллюлозную растительную биомассу. К ее преимуществам можно отнести в первую очередь возобновляемость, практическую неисчерпаемость, а также положительное воздействие на окружающую человека среду из-за возможности преодоления проблемы парникового эффекта, вызванного эмиссией $\mathrm{CO}_{2}$ при использовании нефтехимических и химических технологий, за счет фиксации углекислого газа при выращивании биомассы [1-5]. Благодаря этим преимуществам растительная биомасса может служить практически неисчерпаемой сырьевой базой для

$$
-57 \text { - }
$$


производства материалов, биотоплив и востребованных химических веществ, в том числе так называемых platform molecules - соединений, перспективных для развития промышленности в XXI в. [1-4, 6-10]. Источником лигноцеллюлозной биомассы для новых процессов могут служить: 1) отходы некоторых отраслей промышленности: деревообрабатывающей (отходы древесины), целлюлозно-бумажной (отходы гемицеллюлоз); 2) отходы растениеводства и пищевого производства (солома, кукурузные кочерыжки, шелуха семечек и т.д.); 3) быстрорастущие неценные породы древесины (тополь, ива) и культивируемые на бросовых землях «энергетические культуры», например мискантус.

Растительная биомасса состоит из трех основных компонентов: целлюлозы (содержание в лигноцеллюлозе 40-60 \%), гемицеллюлоз (до 30 \%) и лигнина (10-30 \%) [11-14]. Достаточно высокое содержание гемицеллюлоз в растительном сырье делает поиск способов их переработки достаточно перспективным направлением исследований с точки зрения как переработки чистого сырья на основе гемицеллюлозных полисахаридов, так и создания технологий комплексной переработки лигноцеллюлозной биомассы с вовлечением всех компонентов сырья в процессы превращения без их предварительного выделения и очистки $[15,16]$. К числу распространенных гемицеллюлоз относят арабиногалактан и ксилан. Арабиногалактан (полимер арабинозы и галактозы) широко распространен в хвойных растениях (содержание до 40 \%) [17]. Высокое содержание ксилана, представляющего собой полимер ксилозы, характерно для некоторых перспективных видов сырья из отходов сельского хозяйства (кукурузные початки, коробочки хлопчатника, подсолнечная шелуха и др.) $[14,18]$.

Одним из перспективных направлений комплексной переработки лигноцеллюлозы представляется процесс гидролиза-окисления, позволяющий получать ряд ценных химических веществ с высоким потенциалом применения в топливной и химической промышленностях [19-24], например муравьиную кислоту [19, 25], которая может использоваться в качестве восстановителя или источника водорода при получении топлив из того же растительного сырья [25-28]. Разработаны методы замены молекулярного водорода на муравьиную кислоту, разлагающуюся с выделением водорода в реакционной среде в ходе процессов превращения биомассы в биотопливо [27, 29]. Использование МК как восстановителя имеет ряд преимуществ перед традиционным восстановителем - молекулярным водородом, к недостаткам которого можно отнести повышенные меры безопасности при его хранении и транспортировке, а также сложность и высокую стоимость его получения из биомассы. Кроме того, показана возможность применения муравьиной кислоты в топливных элементах для получения электричества [30].

Процесс получения МК из лигноцеллюлозы или ее основных компонентов состоит из двух последовательных стадий: 1) катализируемой кислотами деполимеризации (гидролиза полисахаридов, делигнификации) и 2) последующего окисления мономеров (моносахаридов, фенольных производных) в МК. Следовательно, для эффективного превращения лигноцеллюлозы в муравьиную кислоту в одностадийном «one-pot» - процессе необходимо создание бифункциональной каталитической системы. Растворы Mo-V-P гетерополикислот (ГПК), известные как катализаторы «зеленой химии» [31], обладающие как кислотными, так и окислительными свойствами, являются перспективными бифункциональными катализаторами [32], в том числе и для получения МК из биомассы [25, 33-37]. Среди преимуществ ГПК можно отметить высокую бренстедовскую кислотность и хорошие окислительные свойства. 
К настоящему времени опубликовано несколько работ, посвященных синтезу МК из полисахаридных компонентов лигноцеллюлозы с использованием в качестве катализаторов бифункциональных Mo-V-P ГПК [25, 33-37]. Наиболее хорошо изученным представляется процесс гидролиза-окисления целлюлозы. Первые исследования по переработке целлюлозы в присутствии Mo-V-P ГПК описаны в работах [38, 39], в которых наблюдалась значительная конверсия целлюлозы, однако авторы ничего не сообщали об образовании МК. В работах $[33,34]$ было проведено исследование гидролиза целлюлозы в присутствии ГПК состава $\mathrm{H}_{5} \mathrm{PV}_{2} \mathrm{Mo}_{10} \mathrm{O}_{40}$ при температуре $90{ }^{\circ} \mathrm{C}$. Авторами работы установлено, что муравьиная кислота была единственным продуктом реакции, зафиксированным в водной среде, а единственным побочным продуктом - $\mathrm{CO}_{2}$ [34]. Целлюлоза оказалась самым трудногидролизуемым объектом (максимальный выход НСООН составил лишь 7 мол. \% за 24 ч реакции). Каталитическая активность ГПК в гидролизе-окислении целлюлозы была систематически исследована в нашей предыдущей работе [40]. Определены оптимальные условия процесса гидролиза-окисления целлюлозы (150 ${ }^{\circ} \mathrm{C}$, давление воздушной смеси 20 атм), исследовано влияние условий реакции на начальную скорость реакции, определена лимитирующая стадия процесса (гидролиз), выявлен оптимальный состав катализатора Mo-V-P ГПК $\left(\mathrm{Co}_{0.6} \mathrm{H}_{3.8} \mathrm{PMo}_{10} \mathrm{~V}_{2} \mathrm{O}_{40}\right)$. В оптимальных условиях нам удалось добиться 66 мол. \% выхода МК из целлюлозы [40]. Близкие значения выходов МК из целлюлозы (68 \%) продемонстрированы в работе [36].

Анализ литературы показал, что в отличие от целлюлозы переработке гемицеллюлозных полисахаридов уделяется значительно меньше внимания. В работах не представлены систематические исследования процесса гидролиза-окисления гемицеллюлоз, направленные в том числе на поиск оптимальных параметров процесса и выяснение влияния условий на выход целевого продукта. В работах $[33,34]$ ксилан использовался как образец сравнения и был переработан в МК в тех же условиях, что и целлюлоза (катализатор ГПК $\mathrm{H}_{5} \mathrm{PV}_{2} \mathrm{Mo}_{10} \mathrm{O}_{40}$, температура $90{ }^{\circ} \mathrm{C}$ ). Выход МК при превращении ксилана составил 40 мол. \%. Арабиногалактан в качестве субстрата для гидролиза-окисления ранее не исследовался.

Наряду с полисахаридами в качестве субстратов используются образцы реальной лигноцеллюлозной биомассы. В работах $[33,34]$ результаты, полученные для целлюлозы, сравнивались с результатами экспериментов, в которых в качестве субстрата взяты такие биологические объекты, как опилки сосны, березы и тополя, а также биомассы цианобактерий. Эксперименты проводились в условиях, использованных для переработки целлюлозы, т.е. в присутствии ГПК состава $\mathrm{H}_{5} \mathrm{PV}_{2} \mathrm{Mo}_{10} \mathrm{O}_{40}$ и при температуре $90{ }^{\circ} \mathrm{C}$. При гидролизе-окислении образцов лигноцеллюлозной биомассы достигнуты выходы от 1 до 26 мол. \% [33, 34], причем лучшие результаты получены для опилок тополя (выход МК 26 мол. \%). Лю и соавт. получили МК с выходом 40 мол. \% из кукурузных кочерыжек при $170{ }^{\circ} \mathrm{C}$ и применении серной кислоты в качестве сокатализатора гидролиза [35]. В работе [36], выполненной совместно исследователями Саудовской Аравии и Китая, в качестве субстратов использовались солома пшеницы и жом сахарной свеклы. В присутствии катализатора ГПК $\mathrm{H}_{4} \mathrm{PVMo}_{11} \mathrm{O}_{40}$ при температуре $180{ }^{\circ} \mathrm{C}$ выходы МК составили около 50 мол. \%.

Целью настоящей работы стало проведение систематических исследований процесса гидролиза-окисления распространенных гемицеллюлоз арабиногалактана и ксилана в МК (рис. 1), в том числе поиск оптимальных условий процесса и выявление взаимосвязи условий 


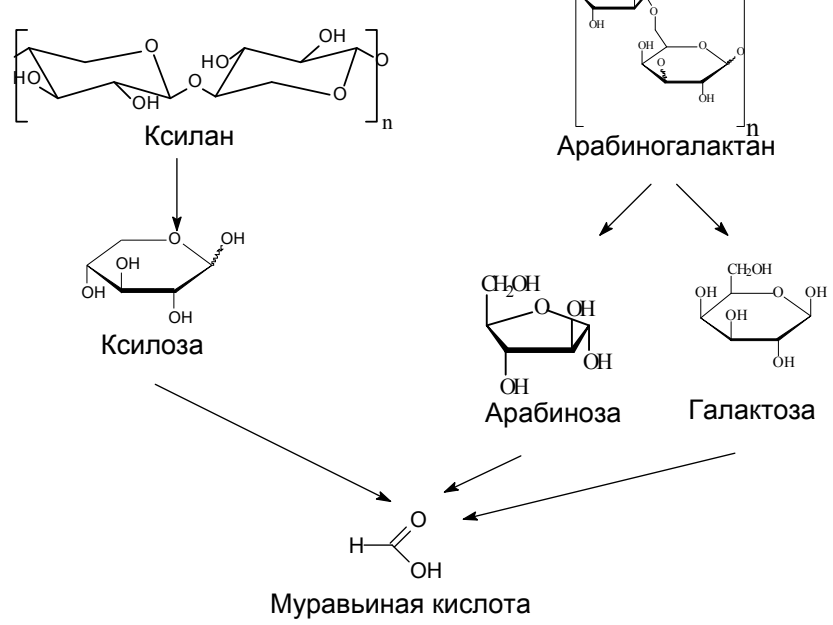

Рис. 1. Схема получения муравьиной кислоты из гемицеллюлоз

Fig. 1. The scheme of formic acid production from hemicelluloses

с выходами МК, а также исследование возможности получения муравьиной кислоты из образцов лигноцеллюлозной биомассы, перспективных для использования в России (древесина осины, сульфатная целлюлоза, газетная бумага и мискантус сибирский). Следует подчеркнуть, что систематические исследования гидролиза-окисления гемицеллюлоз будут способствовать определению оптимальных условий гидролиза-окисления лигноцеллюлозной биомассы в МК без предварительного разделения растительного сырья на компоненты.

\section{Экспериментальная часть}

Pеактивы и материаль. При проведении исследований следующие реактивы использовались без предварительной очистки: оксид ванадия $\mathrm{V}_{2} \mathrm{O}_{5}$ (х.ч., Вектон), оксид молибдена $\mathrm{MoO}_{3}$ (х.ч.), перекись водорода $\mathrm{H}_{2} \mathrm{O}_{2}$ (ос.ч. 8-4), фосфорная кислота $\mathrm{H}_{3} \mathrm{PO}_{4}$ (х.ч., 99.4 \%, Экрос), гидроксикарбонат кобальта $\mathrm{Co}\left(\mathrm{CO}_{3}\right)_{\mathrm{x}}(\mathrm{OH})_{2-2 \mathrm{x}}(45.6 \%$ Со, ч.), ксилан (90 \%, Sigma), арабиногалактан (90 \%, Sigma), D-глюкоза (ч., Реахим), D-ксилоза (90 \%, Panreac), D-арабиноза (98 \%, Acros Organics), D-галактоза (>99 \%, Acros Organics), муравьиная кислота (98 \%, Panreac). Образцы биомассы: сульфатной целлюлозы, древесины осины, мискантуса, газетной бумаги применяли в качестве субстратов. Для окисления брали воздушную смесь $20 \%$ кислорода и 80 \% азота (ГОСТ 5583-78). Дистиллированная вода, дополнительно очищенная на установке Milli-Q (Millipore, Франция), использовалась для приготовления всех растворов.

Приготовление катализатора. Катализатор состава $\mathrm{Co}_{0.6} \mathrm{H}_{3.8} \mathrm{PMo}_{10} \mathrm{~V}_{2} \mathrm{O}_{40}$ готовили по методике, разработанной ранее в Институте катализа СО РАН [41-43], из стехиометрических количеств $\mathrm{V}_{2} \mathrm{O}_{5}, \mathrm{MoO}_{3}, \mathrm{H}_{2} \mathrm{O}_{2}$ и $\mathrm{H}_{3} \mathrm{PO}_{4}$. Оксид ванадия $(\mathrm{V})$ растворяли в холодном растворе пероксида водорода, стабилизировали образовавшуюся на первой стадии декаванадиевую кислоту $\mathrm{H}_{6} \mathrm{~V}_{10} \mathrm{O}_{28}$ фосфорной кислотой и прибавляли к ее кипящему раствору смеси $\mathrm{MoO}_{3}$ и $\mathrm{H}_{3} \mathrm{PO}_{4}$. Состав полученного катализатора раствора ГПК подтверждали методом ЯМР-спектроскопии на ядрах ${ }^{51} \mathrm{~V}$ и ${ }^{31} \mathrm{P}$. Согласно данным ЯМР, раствор катализатора содержал гетерополианионы

$$
-60-
$$


структуры Кеггина с различным числом атомов ванадия, $\mathrm{H}^{+}$-ионы, катионы $\mathrm{VO}_{2}^{+}$, фосфорную кислоту [43].

Определение влажности высушиванием. Влажность полисахаридов и образцов лигноцеллюлозной биомассы определяли по ГОСТ 16932-82. Чистый пустой бюкс (вместе с крышкой в открытом виде) высушивали в сушильном шкафу при (103 \pm 2$)^{\circ} \mathrm{C}$ до постоянной массы. В бюкс помешали навеску биомассы 5 г и сушили в течение 3 ч. После сушки бюкс закрывали крышкой, помещали в эксикатор и после охлаждения взвешивали. Перед взвешиванием крышку бюкса на короткое время приоткрывали, чтобы уравнять давление воздуха. Сушку повторяли по 1 ч (с последующим охлаждением и взвешиванием) до постоянной массы.

Относительную влажность, \%, рассчитывали по формуле (1)

$$
\mathrm{W}=\frac{\mathrm{m}_{1}-\mathrm{m}_{2}}{\mathrm{~m}_{1}-\mathrm{m}} \cdot 100 \%
$$

где $\mathrm{m}$ - масса пустого бюкса (г); $\mathrm{m}_{1}$ - масса бюкса с навеской до высушивания (г); $\mathrm{m}_{2}-$ масса бюкса с навеской после высушивания (г).

Методика проведения процесса гидролиза-окисления полисахаридов и образиов лигноцеллюлозной биомассы в муравьиную кислоту. Процесс проводили в автоклаве высокого давления (Autoclave Engineers, USA) при интенсивном перемешивании (1500 об./мин), давлении воздушной смеси 20 атм, в диапазоне температур 90-180 ${ }^{\circ} \mathrm{C}$. Загрузка субстрата составляла 10 г/л, концентрация катализатора гетерополикислоты состава $\mathrm{Co}_{0.6} \mathrm{H}_{3.8} \mathrm{PMo}_{10} \mathrm{~V}_{2} \mathrm{O}_{40}-10$ ммоль/л (концентрация атомов ванадия в реакционной смеси 20 ммоль/л). Катализатор и субстрат загружали в автоклав, добавляли 60 мл воды. Автоклав закрывали, продували воздушной смесью, устанавливали рабочее давление и начинали подъем температуры. После выхода температуры на режим ( 20 мин) отбирали пробу реакционной смеси для анализа, которую считали нулевой точкой процесса (нулевая проба). Пробы реакционной смеси отбирали для анализа через 0.25 , $0.5,1,2,3,5$ и 7 ч.

Методика анализа реакционных растворов. Концентрации продуктов в водных реакционных растворах определяли методом ВЭЖХ с помощью хроматографа Shimadzu Prominence LC-20 (Япония), оборудованного рефрактометрическим детектором и колонкой Rezex Organic Acids $\mathrm{H}^{+}$(Phenomenex, 300 мм $\times 5.0$ мм), термостатированной при $40{ }^{\circ} \mathrm{C}$. В качестве элюента использовали $2.5 \mathrm{mN}$ водный раствор серной кислоты $\mathrm{H}_{2} \mathrm{SO}_{4}$, скорость потока составляла 0.6 мл/мин.

Расчет выходов продуктов реакиии. Выходы продуктов реакции гидролиза-окисления ксилана и арабиногалактана рассчитывали по формуле (2) в мольных процентах (мол. \%), как в работе [40] для гидролиза-окисления целлюлозы:

$$
\mathrm{Y}_{\mathrm{MK}}=\frac{\mathrm{C}_{\mathrm{MK}} \cdot \mathrm{V}}{\mathrm{N}_{\mathrm{C}} \cdot v_{\text {субстрат }}} \cdot 100 \%
$$

где $\mathrm{Y}_{\mathrm{MK}}$ - выход муравьиной кислоты (мол. \%); $\mathrm{C}_{\mathrm{MK}}$ - концентрация муравьиной кислоты (моль/л); $\mathrm{V}$ - объем реакционной смеси (л); $\mathrm{N}_{\mathrm{C}}$ - фактор мольного соотношения между мономером в молекуле полисахарида и муравьиной кислотой, равный 6 для ксилана и 5.85 для арабиногалактана. 
Выход муравьиной кислоты в процессе гидролиза-окисления образцов биомассы рассчитывали по формуле (3) в массовых процентах (масс. \%) к общей массе субстрата:

$$
\mathrm{Y}_{\mathrm{MK}}=\frac{\mathrm{C}_{\mathrm{MK}} \cdot \mathrm{V} \cdot \mathrm{M}_{\mathrm{MK}}}{\mathrm{m}_{\text {суббстрат }}} \cdot 100 \%,
$$

где $\mathrm{Y}_{\mathrm{Mк}}$ - выход муравьиной кислоты (мас. \%); $\mathrm{C}_{\mathrm{MK}}$ - концентрация муравьиной кислоты в реакционном растворе (моль/л); $\mathrm{V}$ - объем реакционной смеси (л); $\mathrm{M}_{\mathrm{MK}}$ - молярная масса муравьиной кислоты (46.0 г/моль).

\section{Результаты и их обсуждение}

В качестве объектов для исследования были выбраны распространенные гемицеллюлозы: арабиногалактан и ксилан в виде химически чистых реактивов, а также образцы лигноцеллюлозной биомассы: сульфатная целлюлоза (беленая из лиственной древесины (осиновая) ГОСТ 14940-75), опилки древесины осины Pópulus trémula, многолетнее травянистое растение мискантус Сорановский (новый сорт мискантуса китайского, интродуциронного в условиях Западной Сибири [44]), газетная бумага. Исследуемые образцы представляют, соответственно, основные классы перспективных для России источников сырья растительного происхождения для получения муравьиной кислоты: продукты и отходы целлюлозно-бумажной промышленности (на примере сульфатной целлюлозы), неценные породы древесины (осина), многолетние быстрорастущие травянистые растения, произрастающие на не имеющих сельскохозяйственного значения бросовых землях Сибири и Севера России (мискантус), вторичное сырье (бумажные отходы, макулатура на примере газетной бумаги). Образцы биомассы осины были предварительно механически активированы с использованием планетарной мельницы АГО-2, мискантуса - роторной мельницы МАН-30, сульфатной целлюлозы и газетной бумаги измельчены в шнековой мельнице (Maxwell, Кипр).

Полисахариды и лигноцеллюлозная биомасса содержат в своем составе несвязанную воду, количество которой может достигать высоких значений, внося существенный вклад в массу навески субстрата и, как следствие, в расчет выходов целевых продуктов. Для определения действительного соотношения влаги и твердого субстрата в образцах гемицеллюлоз и лигноцеллюлозной биомассы было проведено определение влажности по ГОСТ 16932-82 путем высушивания образцов при температуре $(103 \pm 2){ }^{\circ} \mathrm{C}$ и взвешивания до постоянной массы. Результаты представлены в табл. 1. Для всех образцов характерно умеренное содержание влаги, наличие которой, по-видимому, связано с хранением образцов на открытом воздухе. Выходы продуктов реакции рассчитывались на массу твердого субстрата с учетом определенной влажности образца.

Для создания эффективного процесса переработки растительного сырья необходим поиск оптимальных условий превращения. На процесс гидролиза-окисления полисахаридов и лигноцеллюлозной биомассы могут оказывать влияние температура, давление воздушной смеси, соотношение субстрат:катализатор. Ранее влияние этих условий нами было исследовано для целлюлозы - трудногидролизуемого полисахарида [40]. Определены следующие оптимальные условия: $150{ }^{\circ} \mathrm{C}$, давление воздушной смеси 20 атм. и соотношение атомов ванадия к глюкану $($ остатку глюкозы $)=1: 3$. Температура проведения процесса оказывала наибольшее влияние на

$$
-62-
$$


Таблица 1. Результаты измерения влажности образцов гемицеллюлоз и образцов биомассы растительного происхождения

Table 1. The results of moisture content measurements made for samples of hemicelluloses and real plant biomass

\begin{tabular}{|c|l|c|}
\hline № п/п & \multicolumn{1}{|c|}{ Образец биомассы } & Влажность W, \% \\
\hline 1 & Ксилан & 4.1 \\
\hline 2 & Арабиногалактан & 7.9 \\
\hline 3 & Целлюлоза сульфатная & 2.2 \\
\hline 4 & Древесина осины & 4.5 \\
\hline 5 & Мискантус сибирский & 3.6 \\
\hline 6 & Газетная бумага & н.о. \\
\hline
\end{tabular}

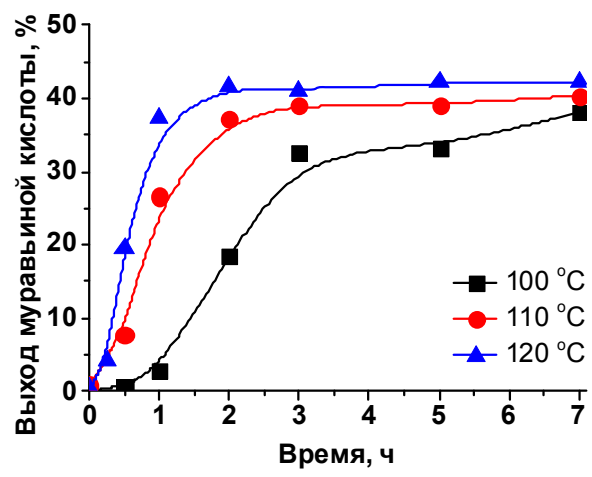

Рис. 2. Кинетические кривые накопления муравьиной кислоты в процессе гидролиза-окисления ксилана. Условия процесса: катализатор ГПК $\mathrm{Co}_{0.6} \mathrm{H}_{3.8} \mathrm{PMo}_{10} \mathrm{~V}_{2} \mathrm{O}_{40}$, [ксилан]=10 г/л, [ГПК]=10 ммоль/л ([V]=20 ммоль/л), объем реакционной смеси 60 мл, давление воздушной смеси 20 атм

Fig. 2. Kinetic curves of formic acid accumulation in the process of xylan hydrolysis-oxidation. Reaction conditions: catalyst of HPA $\mathrm{Co}_{0.6} \mathrm{H}_{3.8} \mathrm{PMo}_{10} \mathrm{~V}_{2} \mathrm{O}_{40}$, [xylan] $=10 \mathrm{~g} / \mathrm{L}$, [HPA] $=10 \mathrm{mmol} / \mathrm{L}$ ([V]=20 mmol/L), the reaction mixture volume was $60 \mathrm{~mL}$ of, air mixture pressure was 20 bar

начальную скорость превращения полисахарида. Использованные в данной работе в качестве субстратов арабиногалактан и ксилан гидролизуются значительно легче, чем целлюлоза, следовательно, жестких условий процесса не требуются. Поэтому температурная зависимость кинетики накопления муравьиной кислоты и её выходов в гидролизе-окислении гемицеллюлоз была исследована при более низких температурах (90-120 $\left.{ }^{\circ} \mathrm{C}\right)$, чем для целлюлозы. Соотношение субстрат:катализатор (3:1) и давление воздушной смеси (20 атм) были выбраны такими же, как для целлюлозы [40]. Полученые кинетические зависимости накопления муравьиной кислоты приведены на рис. 2 и 3.

Исследование реакционных растворов методом ВЭЖХ показали, что муравьиная кислота - основной продукт реакции, причем она не окисляется при проведении длительных экспериментов. Побочными продуктами, обнаруженными при проведении экспериментов, являются соответствующие моносахариды (ксилоза, арабиноза, галактоза), уксусная кислота и формальдегид. Выходы этих продуктов возрастают с ростом температуры с 90 до $120{ }^{\circ} \mathrm{C}$ (табл. 2). Так, 


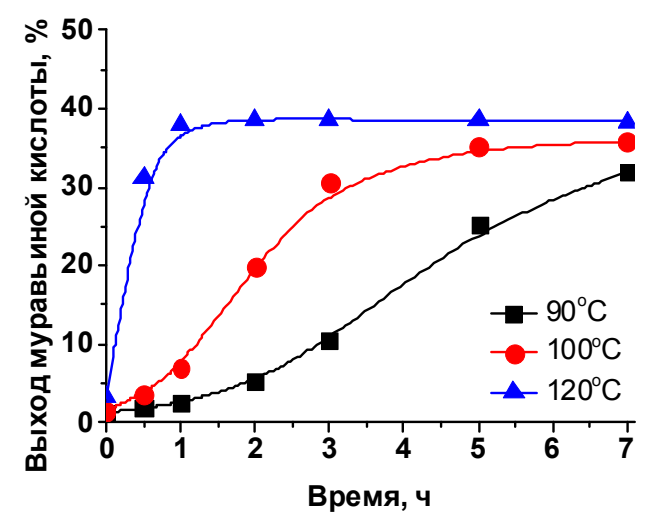

Рис. 3. Кинетические кривые накопления муравьиной кислоты в процессе гидролиза-окисления арабиногалактана. Условия процесса: катализатор ГПК $\mathrm{Co}_{0.6} \mathrm{H}_{3.8} \mathrm{PMo}_{10} \mathrm{~V}_{2} \mathrm{O}_{40}$, [арабиногалактан] $=10$ г/л, $[Г П К]=10$ ммоль/л ([V]=20 ммоль/л), объем реакционной смеси 60 мл, давление воздушной смеси 20 атм

Fig. 3. Kinetic curves of formic acid accumulation in the process of arabinogalactan hydrolysis-oxidation. Reaction conditions: catalyst of $\mathrm{HPA} \mathrm{Co}{ }_{0.6} \mathrm{H}_{3.8} \mathrm{PMo}_{10} \mathrm{~V}_{2} \mathrm{O}_{40}$, [arabinogalactan] $=10 \mathrm{~g} / \mathrm{L}$, [HPA] $=10 \mathrm{mmol} / \mathrm{L}([\mathrm{V}]=20 \mathrm{mmol} / \mathrm{L})$, the reaction mixture volume was $60 \mathrm{~mL}$ of, air mixture pressure was 20 bar

Таблица 2. Выходы продуктов реакции, зафиксированных в исследуемом процессе. Общие условия процесса: концентрация катализатора ГПК-2 $\mathrm{Co}_{0.6} \mathrm{H}_{3.8} \mathrm{PMo}_{10} \mathrm{~V}_{2} \mathrm{O}_{40} 10$ ммоль/л, концентрация субстрата 10 г/л, объем ГПК-2 60 мл, давление воздушной смеси 20 атм

Table 2. The reaction product yields detected under the process. The reaction conditions: the concentration of $\mathrm{Co}_{0.6} \mathrm{H}_{3.8} \mathrm{PMo}_{10} \mathrm{~V}_{2} \mathrm{O}_{40} \mathrm{HPA}$ catalyst was $10 \mathrm{mmo} / \mathrm{L}$, substrate concentration was $10 \mathrm{~g} / \mathrm{L}$, the volume of HPA-2 $60 \mathrm{~mL}$, air mixture pressure $20 \mathrm{bar}$

\begin{tabular}{|c|c|c|c|c|c|c|c|c|c|c|}
\hline \multirow[t]{2}{*}{$\mathrm{N}$} & \multirow[t]{2}{*}{ Субстрат ${ }^{1}$} & \multirow[t]{2}{*}{$\mathrm{T},{ }^{\circ} \mathrm{C}$} & \multicolumn{2}{|c|}{ Моносахарид ${ }^{2}$} & \multicolumn{2}{|c|}{ Формальдегид } & \multicolumn{2}{|c|}{$\begin{array}{c}\text { Уксусная } \\
\text { кислота }\end{array}$} & \multicolumn{2}{|c|}{$\begin{array}{c}\text { Муравьиная } \\
\text { кислота }\end{array}$} \\
\hline & & & $\mathrm{Y}, \%$ & $\mathrm{t}, \mathrm{u}^{3}$ & $\mathrm{Y}, \%$ & $\mathrm{t}, \mathrm{u}^{3}$ & $\mathrm{Y}, \%$ & $\mathrm{t}, \mathrm{u}^{3}$ & $\mathrm{Y}, \%$ & $\mathrm{t}, \mathrm{u}^{3}$ \\
\hline 1 & арабиногалактан & 90 & 5 & 1 & $<1$ & 7 & $<1$ & 7 & 31 & 7 \\
\hline 2 & арабиногалактан & 100 & 8 & 1 & 1 & 3 & 1 & 7 & 36 & 5 \\
\hline 3 & арабиногалактан & 120 & 12 & 0 & 1 & 5 & 2 & 5 & 40 & 1 \\
\hline $4^{4}$ & арабиногалактан & 120 & 11 & 0 & $<1$ & 5 & 2 & 5 & 38 & 1 \\
\hline 5 & ксилан & 100 & 6 & 1 & 1 & 7 & 1 & 3 & 38 & 7 \\
\hline 6 & ксилан & 110 & 8 & $<1$ & 2 & 7 & 1 & 7 & 40 & 3 \\
\hline 7 & ксилан & 120 & 8 & $<1$ & 2 & 3 & 1 & 3 & 42 & 2 \\
\hline 8 & $\begin{array}{l}\text { целлюлоза } \\
\text { сульфатная }\end{array}$ & 150 & $<1$ & 0 & $<1$ & 7 & $<1$ & 7 & 29 & 7 \\
\hline 9 & древесина осины & 150 & 1 & 0.5 & 2 & 2 & 8 & 3 & 53 & 7 \\
\hline 10 & $\begin{array}{l}\text { Мискантус } \\
\text { сибирский }\end{array}$ & 150 & $<1$ & 0.5 & 1 & 3 & 7 & 7 & 45 & 7 \\
\hline 11 & газетная бумага & 150 & $<1$ & 0 & $<1$ & 7 & $<1$ & 7 & 24 & 7 \\
\hline
\end{tabular}

1. Выходы продуктов в процессе превращения арабиногалактана и ксилана приведены в мол. \%, образцов биомассы в мас. \%.

2. Указаны выходы для соответствующих полисахаридам моносахаридов:

ксилозы из ксилана, арабинозы + галактозы из арабиногалактана, глюкозы из целлюлозы.

3. Указаны времена реакции для максимального выхода продукта.

4. Опыт проведен при давлении воздушной смеси 50 атм. 


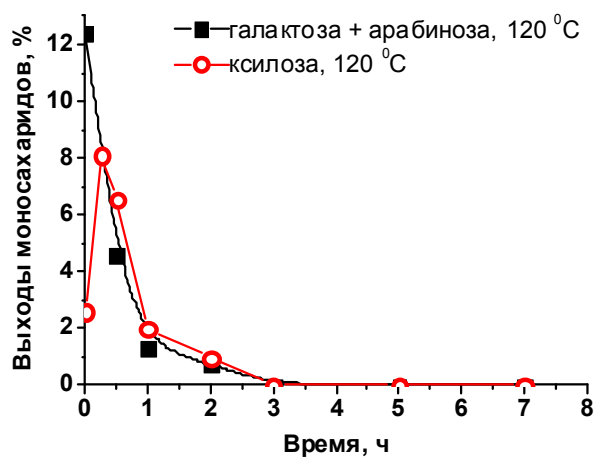

Рис. 4. Зависимость выходов моносахаридов от времени. Условия процесса: температура $120{ }^{\circ} \mathrm{C}$, катализатор ГПК $\mathrm{Co}_{0.6} \mathrm{H}_{3.8} \mathrm{PMo}_{10} \mathrm{~V}_{2} \mathrm{O}_{40}$, [полисахарид]=10 г/л, [ГПК]=10 ммоль/л ([V]=20 ммоль/л), объем реакционной смеси 60 мл, давление воздушной смеси 20 атм

Fig. 4. Reaction time dependence of monosaccharide yields. Reaction conditions: reaction temperature was $120{ }^{\circ} \mathrm{C}$, catalyst of $\mathrm{HPA} \mathrm{Co}_{0.6} \mathrm{H}_{3.8} \mathrm{PMo}_{10} \mathrm{~V}_{2} \mathrm{O}_{40}$, [polysaccharide] $=10 \mathrm{~g} / \mathrm{L},[\mathrm{HPA}]=10 \mathrm{mmol} / \mathrm{L}([\mathrm{V}]=20 \mathrm{mmol} / \mathrm{L})$, the reaction mixture volume was $60 \mathrm{~mL}$, air mixture pressure was 20 bar

для арабиногалактана и для ксилана при небольших временах реакции наблюдались значительные выходы моносахаридов (до 12 мол. \% галактозы и арабинозы для арабиногалактана; 8 мол. \% ксилозы для ксилана при $\left.120^{\circ} \mathrm{C}\right)$, которые быстро уменьшались при увеличении времени реакции (рис. 4). Уже после 2 часов проведения эксперимента выходы моносахаридов составили менее 1 мол. \%, а после 3 часов моносахариды не наблюдались. Такие высокие выходы моносахаридов в первые два часа процесса не зафиксированы при использовании целлюлозы в качестве субстрата [40]. Высокие выходы моносахаридов могут быть вызваны более высокой скоростью гидролиза растворимых в воде полисахаридов ксилана и арабиногалактана по сравнению с активированной микрокристаллической целлюлозой. Выходы уксусной кислоты и формальдегида для обоих исследованных полимеров не превышали 1-2 мол. \% и были сравнимы с выходами в экспериментах с целлюлозой (табл. 2).

Оптимальной для проведения процесса оказалась температура $120{ }^{\circ} \mathrm{C}$, при которой достигнуты наибольшие выходы муравьиной кислоты, равные 43 и 40 мол. \% для ксилана и арабиногалактана соответственно, за 7 ч реакции. Аналогичные выходы муравьиной кислоты, по-видимому, могут быть получены и при более низких температурах, однако для их достижения требуется значительно больше времени. Кинетические кривые образования муравьиной кислоты характеризуются индукционным периодом, связанным с постепенным накоплением в растворе МК, способной выступать в роли сокатализатора гидролиза и увеличивать наблюдаемую скорость реакции. Достигнутые величины выходов муравьиной кислоты в процессе гидролиза-окисления ксилана хорошо согласуются с литературными данными. Альберт и соавторы получили из ксилана муравьиную кислоту с выходом 40 мол. \% [33, 34]. Следует отметить, что данный выход был достигнут за 24 ч реакции, в то время как в данной работе он получен за 7 ч. Однако длительные времена превращения могут объясняться использованием очень низких температур $\left(90^{\circ} \mathrm{C}\right)[33,34]$. Насколько нам известно, это единственная работа, посвященная гидролизу-окислению ксилана в муравьиную кислоту. Исследований возможности превращения в МК арабиногалактана ранее не проводилось.

$$
-65-
$$




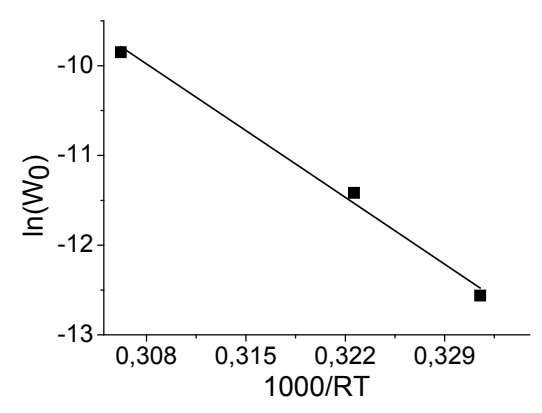

A

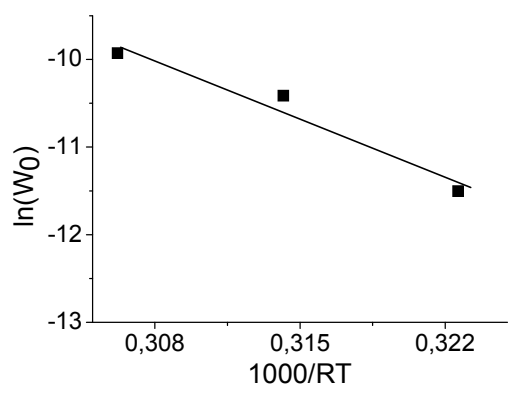

Б

Рис. 5. Зависимость логарифма начальной скорости реакции от обратной температуры процесса: А субстрат арабиногалактан, Б - субстрат ксилан

Fig. 5. Arrhenius temperature dependence of the initial reaction rate: A - arabinogalactan substrate, B - xylan substrate

Из полученных кинетических зависимостей накопления муравьиной кислоты от времени рассчитаны начальные скорости процессов, построены графики зависимости начальной скорости от температуры в аррениусовых координатах (рис. 5). Из графиков рассчитаны наблюдаемые энергии активации ( $\left.\mathrm{E}_{\mathrm{a}}\right)$ процессов для арабиногалактана и ксилана, которые составили 106 и 82 кДж/моль соответственно. Полученные эффективные энергии активации близки к энергии активации для гидролиза-окисления целлюлозы (80 кДж/моль) [40].

В оптимальных условиях на примере полисахарида арабиногалактана исследовано влияние давления воздушной смеси на выходы продуктов и начальную скорость превращения гемицеллюлоз (табл. 2). Исследование влияния содержания кислорода в системе на выход муравьиной кислоты проведено в экспериментах в присутствии катализатора ГПК при оптимальной температуре $120{ }^{\circ} \mathrm{C}$ и фиксированном составе газовой смеси. Для изменения содержания кислорода в системе варьировалось давление газовой смеси. Эксперименты проводились при 20 и 50 атм. Установлено, что давление кислорода, как и в случае с целлюлозой, не влияет на начальную скорость выделения муравьиной кислоты [40]. Таким образом, на основании отсутствия влияния давления кислорода на начальную скорость реакции превращения полисахаридов и значения энергии активации, близкие к значениям, найденным для целлюлозы, можно предположить, что гидролиз является лимитирующей стадией процесса гидролиза-окисления гемицеллюлозных полисахаридов ксилана и арабиногалактана.

Лигноцеллюлозная биомасса может содержать до 80 \% полисахаридов (целлюлозы и гемицеллюлоз), которые могут быть использованы как сырье для получения муравьиной кислоты. Вместе с тем выделение и очистка сырья, содержащего полисахариды, представляется довольно затратной процедурой, поэтому перспективен поиск путей получения целевого продукта напрямую из первичного лигноцеллюлозного сырья. В нашей работе испытаны размолотые образцы (1) сульфатной целлюлозы, (2) древесины осины, (3) мискантуса сорановского и (4) газетной бумаги.

Так как основным полисахаридным компонентом исследованных образцов лигноцеллюлозы является целлюлоза, опыты с образцами реальной биомассы проводились в условиях,

$$
-66-
$$


оптимизированных для переработки целлюлозы [40]. Опыты осуществляли в автоклаве при температуре $150{ }^{\circ} \mathrm{C}$ и давлении воздушной смеси 20 атм в присутствии катализатора ГПК. Наилучших результатов удалось добиться при использовании в качестве субстратов древесины осины и мискантуса. Выходы муравьиной кислоты после 7 часов реакции составили 53 и 43 мас. \% соответственно. Методом ВЭЖХ зафиксировано образование моносахаридов в небольших количествах (<1 мас. \%) и обнаружено образование уксусной кислоты с заметными выходами до 8 мас. \%, в несколько раз превышающими значения выходов при переработке целлюлозосодержащих субстратов (сульфатной целлюлозы и газетной бумаги) (<1 мас. \%). Невысокие выходы уксусной кислоты (до 2 мол. \%) также наблюдались при переработке полисахаридов ксинала и арабиногалактана (табл. 2), а также ранее при переработке чистой целлюлозы [40]. Полагаем, что уксусная кислота в заметных количествах может образовываться при окислении лигнина и его составляющих. Из литературы известно, что при каталитической окислительной делигнификации биомассы основными продуктами выступают фенол и его производные [22], в то же время уксусная кислота является стабильным интермедиатом аэробного каталитического окисления фенолов в водной среде $[45,46]$.

Полученные результаты экспериментов по гидролизу-окислению мискантуса и осины в несколько раз лучше по сравнению с опытами, с которых в качестве субстрата использовались сульфатная целлюлоза и газетная бумага (после 7 ч реакции выходы 29 и 24 мас. \% соответственно). Причина подобных низких выходов муравьиной кислоты при превращении субстратов со значительным содержанием целлюлозы, таких как сульфатная целлюлоза и бумага, может заключаться в недостаточной глубине активации субстратов [40]. Интересно также отметить, что на всем протяжении процессов гидролиза-окисления образцов лигноцеллюлозной биомассы выходы муравьиной кислоты не выходят на плато и продолжают расти, что свидетельствует о том, что реакция не закончилась и выходы целевого продукта могут быть увеличены (рис. 6). Выходы, достигнутые в данной работе в гидролизе-окислении образцов лигноцеллюлозы, заметно превышают литературные данные. Так, в работах $[33,34]$ при

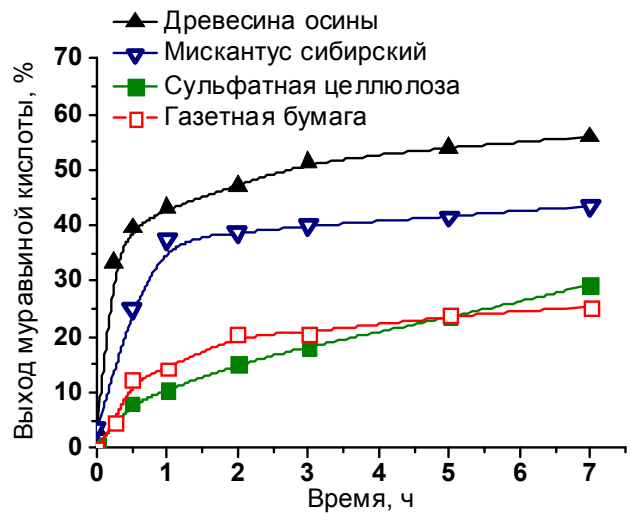

Рис. 6. Кинетические кривые накопления муравьиной кислоты с использованием в качестве субстрата образцов растительной биомассы. Условия проведения процесса аналогично [40]

Fig. 6. Kinetic curves of formic acid accumulation when samples of real plant biomass were used as substrates. Reaction conditions were equal to [40] 
гидролизе-окислении обычной и фильтровальной бумаги были достигнуты выходы МК, равные 5.5 и 1 мол. \% соответственно, что составляет 1.5 и 0.5 мас. \%. Столь низкие выходы могут объясняться как отсутствием какой-либо активации субстратов, так и низкими температурами реакции, недостаточными для эффективного гидролиза-окисления целлюлозы [40]. Мискантус сибирский и древесина осины впервые использованы в качестве сырья, перспективного для получения ценного продукта муравьиной кислоты.

\section{Выводы}

В работе впервые проведено систематическое исследование гидролиза-окисления гемицеллюлоз ксилана и арабиногалактана в муравьиную кислоту, являющуюся перспективным восстановителем и/или источником водорода в процессах производства биотоплив, в присутствии растворов бифункционального катализатора Mo-V-P гетерополикислоты состава $\mathrm{Co}_{0.6} \mathrm{H}_{3.8} \mathrm{PMo}_{10} \mathrm{~V}_{2} \mathrm{O}_{40}$. Арабиногалактан впервые был использован в качестве субстрата в процессе получения МК в присутствии катализатора ГПК. Определены оптимальные условия проведения реакции: температура $120^{\circ} \mathrm{C}$, давление воздушной смеси 20 атм., в которых достигнут выход муравьиной кислоты 40-43 мол. \%. Полученные в процессе переработки значения ксилана хорошо соотносятся с литературными данными.

В оптимальных условиях (температура $150{ }^{\circ} \mathrm{C}$, давление воздушной смеси 20 атм, катализатор состава $\mathrm{Co}_{0.6} \mathrm{H}_{3.8} \mathrm{PMo}_{10} \mathrm{~V}_{2} \mathrm{O}_{40}$ ), подобранных нами по результатам настоящей работы и предыдущего исследования, посвященного переработке целлюлозы [40], выполнены исследования процесса гидролиза-окисления образцов реальной растительной биомассы: древесины осины, мискантуса сорановского, сульфатной целлюлозы и газетной бумаги, представляющихся перспективными источниками сырья для получения МК в России. Мискатус и древесина осины впервые использованы в качестве субстратов для гидролиза-окисления в МК в присутствии ГПК. Получены высокие выходы муравьиной кислоты, равные 53 и 45 мас. \% при использовании осины и мискантуса соответственно. При использовании целлюлозосодержащего сырья (сульфатной целлюлозы и газетной бумаги) достигнуты умеренные выходы МК, которые составили 24-29 мас. \%. Величины выходов заметно превышают литературные данные, а их умеренные величины объясняются устойчивостью кристаллической структуры целлюлозы и необходимостью введения стадии предварительной активации сырья.

Работа выполнена при финансовой поддержке Российского фонда фундаментальных исследований (проект №17-43-540664).

\section{Список литературы}

1. Bhaumik, P., Dhepe, P. L. Solid acid catalyzed synthesis of furans from carbohydrates. Catalysis Reviews 2016. Vol. 58(1), P. 36-112.

2. Murzin, D., Salmi, T. Catalysis for Lignocellulosic Biomass Processing: Methodological Aspects. Catalysis Letters 2012. Vol. 142(6), P. 676-689.

3. Van de Vyver, S., Geboers, J., Jacobs, P. A., et al. Recent Advances in the Catalytic Conversion of Cellulose. Chem CatChem. 2011. Vol. 3, P. 82-94. 
4. van Putten, R.-J., van der Waal, J. C., de Jong, E., et al. Hydroxymethylfurfural, A Versatile Platform Chemical Made from Renewable Resources. Chemical Reviews 2013. Vol. 113(3), P. 1499-1597.

5. Besson, M., Gallezot, P., Pinel, C. Conversion of Biomass into Chemicals over Metal Catalysts. Chemical Reviews 2014. Vol. 114(3), P. 1827-1870.

6. Gallezot, P. Conversion of biomass to selected chemical products. Chemical Society Reviews 2012. Vol. 41(4), P. 1538-1558.

7. Mukherjee, A., Dumont, M.-J., Raghavan, V. Review: Sustainable production of hydroxymethylfurfural and levulinic acid: Challenges and opportunities. Biomass and Bioenergy 2015. Vol. 72. P. 143-183.

8. Кузнецов, Б. Н. Каталитическая химия растительной биомассы. Соросовский образовательный журнал 1996. Vol. 12, C. 47-55. [Kuznetsov, B. N. Catalytic Chemistry of Plant Biomass. Soros Educational Journal 1996. Vol. 12. P. 47-55 (In Russ.)]

9. Klass, D. L. Biomass for Renewable Energyю Fuels and Chemicals. Encyclopedia of Energy. Volume 1. Cutler J. Cleveland. San Diego: Elsevier, 1998. P. 193-212.

10. Kamm, B., Gruber, P. R., Kamm, M. Biorefineries Industrial Processes and Products. Encyclopedia of Industrial Chemistry. Hubert Pelc. Weinheim: VCH Verlag, 2006. P. 659-683.

11. Deutschmann, R., Dekker, R. F. H. From plant biomass to bio-based chemicals: Latest developments in xylan research. Biotechnology Advances 2012. Vol. 30(6), P. 1627-1640.

12. Heinze, T. Chemical Functionalization of Cellulose. Polysaccharides. Structural diversity and functional versatility. Second edition. Severian Dumitriu. - New York: Marcel Dekker, 2005. P. 551.

13. Ruppert, A. M., Weinberg, K., Palkovits, R. Hydrogenolysis Goes Bio: From Carbohydrates and Sugar Alcohols to Platform Chemicals. Angew. Chem. Int. Ed 2012. Vol. 51(11), P. 2564-2601.

14. Spiridon, I. Hemicelluloses: structure and properties. Polysaccharides. Structural diversity and functional versatility. Second edition. Severian Dimitriu. New York: Marcel Dekker, 2005. P. 475487.

15. Gallezot, P., Kiennemann, A. Conversion of Biomass on Solid Catalysts. Handbook of Heterogeneous Catalysis. Ertl. Wiley-VCH Verlag GmbH \& Co. KGaA, 2008. P. 2447-2476.

16. Bruggink, A., Schoevaart, R., Kieboom, T. Concepts of Nature in Organic Synthesis: Cascade Catalysis and Multistep Conversions in Concert. Organic Process Research \& Development 2003. Vol. 7(5), P. 622-640.

17. Rinaldi, R.,Schuth, F. Design of solid catalysts for the conversion of biomass. Energy \& Environmental Science 2009. Vol. 2(6), P. 610-626.

18. Kusema, B. T., Faba, L., Kumar, N., et al. Hydrolytic hydrogenation of hemicellulose over metal modified mesoporous catalyst. Catalysis Today 2012. Vol. 196(1), P. 26-33.

19. Deng, W., Zhang, Q., Wang, Y. Catalytic transformations of cellulose and cellulose-derived carbohydrates into organic acids. Catalysis Today 2014. Vol. 234, P. 31-41.

20. Moreau, C., Belgacem, M. N., Gandini, A. Recent Catalytic Advances in the Chemistry of Substituted Furans from Carbohydrates and in the Ensuing Polymers. Topics in Catalysis Vol. 27(1), P. 11-30.

21. Hustede, H.-J., Haberstroh, E. S. Gluconic Acid. Ulmann's Encyclopedia Industrial Chem. 5th Edition. Volume A12. Hans Jorgen Arpe. - Hamburg: Wiley-VCH Verlag GmbH \& Co., 1989. P. 449456. 
22. Behling, R., Valange, S., Chatel, G. Heterogeneous catalytic oxidation for lignin valorization into valuable chemicals: what results? What limitations? What trends? Green Chemistry 2016. Vol. 18(7), P. 1839-1854.

23. Geboers, J., Van de Vyver, S., Ooms, R., et al. Chemocatalytic conversion of cellulose: opportunities, advances and pitfalls. Catalysis Science\&Technology 2011. Vol. 1, P. 714-726.

24. Deng, W., Zhang, Q., Wang, Y. Polyoxometalates as efficient catalysts for transformations of cellulose into platform chemicals. Dalton Transactions 2012. Vol. 41(33), P. 9817-9831.

25. Li, J., Ding, D.-J., Deng, L. , et al. Catalytic Air Oxidation of Biomass-Derived Carbohydrates to Formic Acid. ChemSusChem 2012. Vol. 5(7), P. 1313-1318.

26. Liu, X., Li, S., Liu, Y., et al. Formic acid: A versatile renewable reagent for green and sustainable chemical synthesis. Chinese Journal of Catalysis 2015. Vol. 36(9), P. 1461-1475.

27. Bulushev, D. A., Ross, J. R. H. Towards Sustainable Production of Formic Acid. ChemSusChem Vol. P. n/a-n/a.

28. Fellay, C., Dyson, P. J., Laurenczy, G. A Viable Hydrogen-Storage System Based On Selective Formic Acid Decomposition with a Ruthenium Catalyst. Angewandte Chemie International Edition 2008. Vol. 47(21), P. 3966-3968.

29. Serrano-Ruiz, J. C., Braden, D. J., West, R. M., et al. Conversion of cellulose to hydrocarbon fuels by progressive removal of oxygen. Applied Catalysis B: Environmental 2010. Vol. 100. P. 184-189.

30. Weber, M., Wang, J. T., Wasmus, S., et al. Formic Acid Oxidation in a Polymer Electrolyte Fuel Cell: A Real-Time Mass-Spectrometry Study. Journal of The Electrochemical Society 1996. Vol. 143(7), P. L158-L160.

31. Rafiee, E., Jafari, H. A practical and green approach towards synthesis of dihydropyrimidinones: Using heteropoly acids as efficient catalysts. Bioorganic \& Medicinal Chemistry Letters 2006. Vol. 16(9), P. 2463-2466.

32. Zhizhina, E. G., Matveev, K. I., Russkikh, V. V. Catalytic Synthesis of 1,4-Naphtho- and 9,10Anthraquinones According to the Diene Synthesis Reaction for Pulp and Paper Industry. Chemistry for Sustainable Development 2004. Vol. 12(1), P. 47-51.

33. Wolfel, R., Taccardi, N., Bosmann, A., et al. Selective catalytic conversion of biobased carbohydrates to formic acid using molecular oxygen. Green Chemistry 2011. Vol. 13(10), P. 27592763.

34. Albert, J., Wolfel, R., Bosmann, A., et al. Selective oxidation of complex, water-insoluble biomass to formic acid using additives as reaction accelerators. Energy \& Environmental Science 2012. Vol. 5(7), P. 7956-7962.

35. Lu, T., Hou, Y., Wu, W., et al. Formic acid and acetic acid production from corn cob by catalytic oxidation using O2. Fuel Processing Technology 2018. Vol. 171, P. 133-139.

36. Zhang, J., Sun, M., Liu, X., et al. Catalytic oxidative conversion of cellulosic biomass to formic acid and acetic acid with exceptionally high yields. Catalysis Today 2014. Vol. 233, P. 77-82.

37. Reichert, J., Albert, J. Detailed Kinetic Investigations on the Selective Oxidation of Biomass to Formic Acid (OxFA Process) Using Model Substrates and Real Biomass. ACS Sustainable Chemistry \& Engineering 2017. Vol. 5(8), P. 7383-7392.

38. Evtuguin, D. V., Pascoal Neto, C., Pedrosa De Jesus, J. D. Bleaching of kraft pulp by oxygen in the presence of polyoxometalates. Journal of Pulp and Paper Science 1998. Vol. 24(4), P. 133-140. 
39. Shatalov, A. A., Evtuguin, D. V., Pascoal Neto, C. Cellulose degradation in the reaction system $\mathrm{O} 2 /$ heteropolyanions of series $\left[\mathrm{PMo}_{(12-\mathrm{n})} \mathrm{V}_{\mathrm{n}} \mathrm{O}_{40}\right]_{(3+\mathrm{n})}{ }^{-}$. Carbohydrate Polymers 2000. Vol. 43(1), P. 2332.

40. Gromov, N. V., Taran, O. P., Delidovich, I. V., et al. Hydrolytic Oxidation of Cellulose to Formic Acid in the Presence of Heteropoly Acid Catalysts for Efficient Processing of Lignocellulosic Biomass. Catalysis Today 2016. Vol. 278(1), P. 74-81.

41. Odyakov, V. F., Zhizhina, E. G. A novel method of the synthesis of molybdovanadophosphoric heteropoly acid solution. Reaction. Kinetics and Catalysis Letters 2008. Vol. 95(1), P. 21-28.

42. Odyakov, V. F., Zhizhina, E. G., Maksimovskaya, R. I. Synthesis of molybdovanadophosphoric heteropoly acid solutions having modified composition. Applied Catalysis A: General 2008. Vol. 342(1-2), P. 126-130.

43. Одяков, В. Ф., Жижина, Е. Г., Максимовская, Р. И. и др. Новые методы синтеза молибдованадофосфорных гетерополикислот. Кинетика и катализ 1995. Vol. 36(5), С. 795-300. [Odyakov, V. F., Zhizhina, E. G., Maksimovskaya, R. I., Matveev, K. I. New methods for the synthesis of molybdovanadophosphoric heteropolyacids. Kinetics and catalysis 1995. Vol. 36(5), P. 795-300 (In Russ.)]

44. Shumniy, V. K., Veprev, S. G., Nechiporenko, N. N., Goryachkovskaya, T. N., Slynko, N. M., Kolchanov, N. A., Peltek, S. E. A new form of Miscanthus Chinese (Silvergrass Chinese Miscanthus Sinensis Anders.) As a promising source of cellulose-containing raw materials. Vestnik VOGiS 2010. Vol. 14(1) P. 122-126.

45. Santos, A., Yustos, P., Quintanilla, A., et al. Route of the catalytic oxidation of phenol in aqueous phase. Applied Catalysis B: Environmental 2002. Vol. 39(2), P. 97-113.

46. Devlin, H. R., Harris, I. J. Mechanism of the oxidation of aqueous phenol with dissolved oxygen. Industrial \& Engineering Chemistry Fundamentals 1984. Vol. 23(4), P. 387-392. 